\title{
Воспоминания о Викторе Калнине
}

\author{
Арнис Виксна
}

Когда же это было? Как давно и много ли времени утекло? Ровно тридцать лет тому назад в яркий и солнечный осенний день 1969 года, когда у деревьев уже были чуть пожелтевшие листья, около тяжелых дверей нашего музея стоял и курил сигарету солидный и спокойный, симпатичный мужчина среднего роста и возраста с полысевшей головой и, сердечно улыбаясь, беседовал с приятной дамой, у которой были длинные светлые волосы. Дама, а это была Айя Дирбе, с которой я уже пару недель сидел в одном кабинете и которая являлась моим первым трудовым воспитателем по музейному делу, поэтому ее сильно респектировал и даже немножко боялся, - познакомила нас Калныньшем? Наверно он латыш, я сразу подумал, но Виктор Владимирович, как тогда по русскому обычаю мы друг друга чествовали, оказалось, ничего больше как sveiki и paldies по-латышски не знал, а позже о своем латышском происхождении говорить стеснялся. В тот раз он меня неожиданно при первом же разговоре пригласил участвовать на 8-й Балтийской конференции по истории науки, которую он организовал, и я сразу за пару дней подготовил и направил ему в Тарту тезисы, ибо мне предстояла защита диссертации и публикации были необходимы.

В то время мне было 27 лет, и не имея места на кафедре после аспирантуры, я только что был направлен на работу в Музей истории медицины им. П. Страдыня, в котором проработал последующие 29 лет. Я был на 13 лет моложе Виктора, поэтому сначала наши отношения были как между опытным старшим товарищем и молодым начинающим, как это и должно было быть, но позже постепенно разница стерлась и сгладилась. Ведь у нас были общие интересы и та же направленность по одной и единственной для нас и для нашей жизни тропе.

Следующая встреча состоялась уже в Тарту в конце июня или начале июля 1970 года, когда я вместе с Айей и известным палеопатологом стариком Вилисом Дерумсом прибыл на конференцию. Это также был важный момент в моей жизни, ибо при помощи случайной поддержки со стороны 
Виктора я вошел в среду балтийских историков науки, в которой остаюсь до сих пор, но уже на другом уровне. В тот раз, как ни странно, в Тарту, а не в Риге, я впервые лично познакомился (до того видел только на трибуне) с академиком Янисом Страдынем, который также в дальнейшем оказал на меня определенное влияние. Конференция прошла успешно. Помню, что Виктор мое выступление на плохом русском языке немножко подправил. Состоялись экскурсии по университету и городу, а также на катере по реке до озера, перед которым я сделал фотоснимок, который у меня

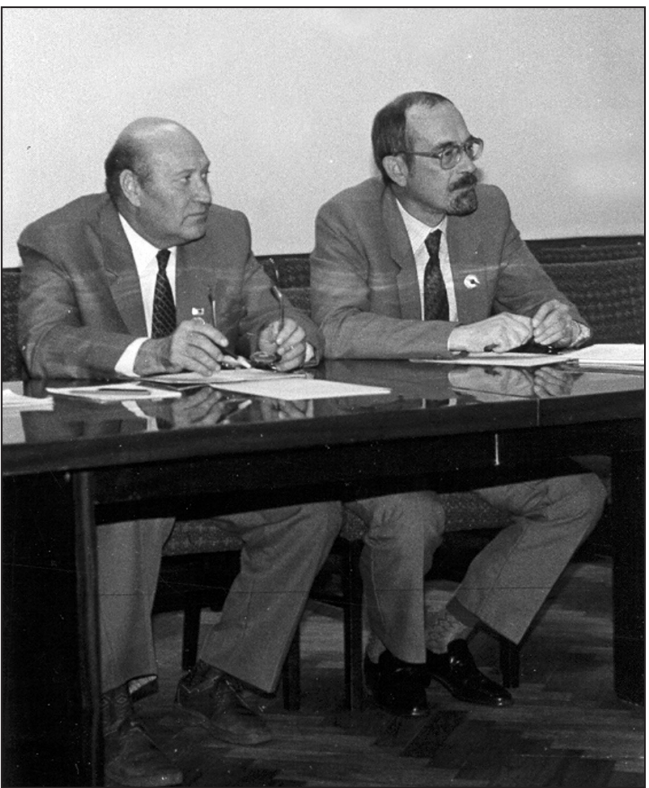

Виктор Калнин и Арнис Виксна ведут заседание секции истории медицины на 15-й Балтийской конференции по истории науки. Рига, 30 сентября 1987 года сохранился.

В дальнейшем я довольно часто приезжал в Тарту на работу в архиве, интересуясь латышскими медиками - воспитанниками университета, где Виктор мне оказывал значительную методическую помощь. Мы стали видеться все чаще и чаще - как в Риге и Тарту, так и в других местах. Обычно образовались достаточно длинные и содержательные беседы о нашей специальности, а также о частных взаимно интересующих вопросах истории медицины. Виктор был достаточно опытным советником, давал полезные указания и рекомендации, помогал и поддерживал. В этот период, кажется, я его сильно использовал, так как в то время моя отдача перед ним была значительно мизерней. Мы начали готовить также совместные публикации. Пытаясь освоить историографию медицины Балтии, на первом месте оказался Изидор Бренсон, наследниками которого мы себя считали, но, к сожалению, до его уровня ни Виктору, ни мне позже подняться так и не удалось.

В памяти всплывают малозначительные, но иногда достаточно выразительные и яркие моменты наших встреч. В Кишиневе, например, на 1-м Всесоюзном съезде историков медицины в 1973 году делегация Эстонии со- 


\section{А. Виксна}

стояла из двух человек (еще приятная блондинка Салме Ахелик из Таллина), а в латвийской делегации было человек десять. По приглашению Виктора я присоединился к эстонской. Шефом делегации был главврач местной санэпидстанции. Он на своей машине нас возил по винозаводам и демонстрировал свою власть, что выразилось в непрерывном любезном угощении. Видели, как на самосвале привозят грязный виноград, потом дальнейший процесс переваривания, как бочкари огромными топорами делают дубовые бочки высотой в два человеческих роста, даже небольшая компания поместилась бы в подобной бочке, превращенной в миниатюрный кабачок.

А в Томске, где разница времени составляла четыре часа, мы с Виктором однажды в гостинице дружно проспали как раз четыре часа от начала заседания. Когда самолетом вернулись в Москву, вылетели в 8 часов и прилетели также в 8 часов, ибо полет продолжался четыре часа. В Москве аэропорт был переполнен, и, ожидая рижского самолета, мы до следующего утра ночевали, с трудом найдя место около стены на полу, где сидя дремали, зажав сумки между ног. Ночью я проснулся от громкой руганьи, - оказывается, Виктор поднялся и на минуту вышел, а за это время его место со мной рядом занял уже другой человек, который даже успел заснуть. Виктор сердито его будил, чтобы тот отдал ему место.

За то в Самарканде в декабре месяце мы время провели отлично, для нас вполне приемлемых климатических условиях. Гуляли и удивлялись четырьмя М - медрес, мошея, минарет, мавзолей. Там был похоронен также брат Мухамеда. Паломник для отпущения грехов, если в своей жизни неможет попасть в Мекку, должен был хотя бы могилу брата посетить, но чтобы избавиться от грехов, два раза. Я побывал в Самарканде два раза, Виктор только один раз - но мы ведь не мусульмане...

По своему характеру Виктор, как мне кажется и насколько я его знал, был довольно тихим и спокойным человеком, правда, иногда очень критично высказывался о некоторых коллегах, и по всей вероятности был прав. Не знаю, именно почему, но в его жизни постепенно начались большие осложнения, наступили тяжелые дни, и в конце концов он был вынужден прекратить преподавательскую работу в университете, а также уйти из дома. Это было около 1978 года. Он даже просился на работу в Ригу, но мы не могли его обеспечить достаточно хорошо оплачиваемой должностью, может быть, начальство этого не хотело. О судьбе Виктора как опытного историка медицины, которого нельзя так просто потерять, заволновались не сами эстонцы, а профессор Павел Ефимович Заблудовский в Москве, который просил Карла Арона выяснить ситуацию. Но у Арона не было времени или желания, и в Тарту решил поехать я. Приехал я в неприятный, темный день - дождь, грязь, снег и слякоть. Виктор спрашивает:

- Зачем приехал?

- Просто так, поработать в архиве. 
- А когда отъезжаешь?

- Наверно, вечером.

- Какая тогда у тебя работа в архиве на пару часов!

Так он сразу отгадал меня, хотя делать из себя спасательную экспедицию я не собирался. Грустное лицо и собенно глаза Виктора как-будто посветлели, почуствовалось доверие и доброта ко мне. Кажется, что с этого момента мы по настоящему подружили, хотя от вы на ты перешли уже раньше. О причинах в прошлом и перспективах решения личных бед и несчастий Виктора в дальнейшем мы не говорили (в скором времени, спустя год или два, он вернулся в университет), а только о своих обыденных и общих историкомедицинских делах. Помню, в то время он жил на окраине города в каком-то полупогребе без всяких удобств в маленькой комнатушке, где была только кровать, да бесчисленные бумаги. Так как там была печь, Виктор в жестянку положил картошку и свинину и в печи на красных горячих углях испек. Получился отличный и очень вкусный ужин, дополненный собраннымы и замаринованнымы самим Виктором грибамы. Он рассказал рецепт - после варения воду не надо сливать и грибы полоскать, а мариновать в той же жидкости - грибы получаются черные и неприглядные, за то какой вкус!

О личной жизни Виктора до того времени знаю мало. Его первую супругу, кажется, видел один или два раза, и мне показалось, что она очень сердитая, но возможно я не прав. За то Майя очень заботилась о Викторе, оберегала его, не пускала в шумные компании, как, например, в Ташкенте на 2-м Всесоюзном съезде историков медицины в 1980 году, где мы, остальные, порядочно развлекались как на базаре, так и, извините меня, на кладбище. И правильно делала! Мне кажется, что только благодаря Майе Виктору удалось встать на ноги после последующего инфаркта в 1982 году и еще достаточно долго и плодотворно поработать. Правда, может быть Майе будет неприятно, если я открою одну маленькую тайну, - Виктор все же продолжал тайком курить - одну сигарету в день...

Но особенно мне запомнилась наша совместная экскурсия в Квистенталь. В то время я писал книгу о Дерптском Университете и меня очень интересовала вдохновляющая жизнь студентов XIX века, когда поездки и развлечения в Квистентале занимали определенное место. Перед выездом на лодках, из пушки, которая стояла у каменного моста, был произведен даже торжественный выстрел! У Майи был легковой автомобиль, и она решили мою любознательность удовлетворить. И так, взяв с собой собаку, мы поехали в Квистенталь. Но там ничего особенного - берег реки, какие-то кусты, ни одного старого здания, даже руин по кабаку не осталось, - серо и скучновато. Побеседовали и через некоторое время вернулись в Тарту. Но впечатление осталось неизгладимое - ведь я побывал в Квистентале!

Мероприятия, на которых мы чаще встречались, можно разделить на несколько уровней. Конечно, были и просто личные встречи, когда я при- 


\section{А. Виксна}

езжал в Тарту, чтобы поработать, но чаще это было во время разных конференций, конгрессов, симпозиумов, курсов. Регулярно, через два-три года, проводились балтийские конференции историков науки, на которых обыкновенно Виктор был среди организаторов медицинской секции, позже также и я, если они проводились в Риге. Почти ежегодно проводились сессии по истории Тартуского Университета, а также различные заседания у нас в Риге. Ежегодно также созывался пленум правления Всесоюзного историко-медицинского общества, который обыкновенно проходил одновременно с выездным циклом по истории медицины, который организовал Центральный институт усовершенствования врачей (ЦИУВ). Среди балтийских коллег в Риге, Тарту, Каунасе, Вильнюсе, Таллинне мы обыкновенно чувствовали себя как дома, но иначе было в Союзе, когда на нас ложилось уже определенное представительство, вот, такие балтийцы... Но об этом немного подробней.

Циклы ЦИУВ, которые вел профессор П. Е. Заблудовский, а потом его воспитанник и преемник доцент Эдуард Дмитриевич Грибанов, проходили сначала в Москве, а примерно с 1972 года начали проходить в разных городах огромной страны, начиная с Архангельска и кончая даже Владивостоком. Правда, мы с Виктором не всегда и не ежегодно участвовали. Циклы были двух калибров - для профессорско-доцентского состава, и ассистентские, при том веселее было на последних. Усовершенствование сопровождалось большой экскурсионной программой, так что побывали как на Кавказе, так и в Средней Азии, Сибири и других местах. Если Заблудовский, который уже был очень старым (он достиг 99-летнего возраста), лекции читал на удовлетворительном уровне, то Грибанов довольно поверхностно, да и не любил это делать, демонстрировал медали из своей коллекции, а докладывать просил участников. Так мы говорили и обсуждали каждый о своем. В целом уровень был невысоким, за то польза была от индивидуального общения, бесед, сближений, ибо свободного времени было предостаточно, при том наш круг был довольно узким и мы лично знали друг друга, а историков медицины по всему Союзу было около 100. Иногда мы иронизировали, что важнейшие научные вопросы решаются в баре за рюмкой, когда человек становится откровенней и доступней, и, чего таить, так это и было.

За то всесоюзные и подобные научные встречи коллег историков медицины всегда отличались громким и ярким ораторствованием, что очень ценилось и считалось доказательством эрудиции и компетентности выступающего. Царило краснобайство и пустозвонство. Особенно преуспевал Борис Дмитриевич Петров, также Юрий Павлович Лисицын (пропагандировал новую науку - санологию) и примкнувший к ним Миша Яровинский ("Пирогов - солнце на небосводе всемирной медицины!"), соревнуясь между 
собой наподобые средневековых схоластов. Из латвийских коллег ораторствовать любили Аркадий Хазанов и Карл Арон с той разницей, если у первого хотя еще было что сказать, то у второго - театральные жесты, длинные паузы, крылатые выражения на латинском языке и подходящий к соответствующему моменту достаточно яркий лозунг в заключении. Всячески хвалили советский строй и компартию, доказывали всемирное значение так называемой отечественной медицины, критиковали буржуев, капиталистов и националистов. Кажется, что серьезности было мало. Строгую фактографию, серьезную работу над источниками не слишком одобряли и ценили, достаточно было отдельных необходимых примеров и цитат из трудов классиков марксизма-ленинизма.

В отличие от других подобных исследователей, Виктор выделялся на фоне общего невысокого уровня тем, что его выступления всегда были хорошо подготовлены и разработаны на достаточно солидном фактическом материале. Правда, он выступал негромко, иногда маловыразительно, не пользовался жестами, не стучал кулаком по трибуне, не делал паузы, но за то приводил убедительные доказательства и приходил к логическому выводу. Выглядел он всегда корректно и солидно, внушающим доверие. Недолгое время, пару лет, Виктор носил бороду, но так как та с боков начала седеть, я однажды поиронизировал о перевернутом трехполосом латвийском флаге (у которого белая полоса по середине). На что Виктор мог вполне мне дать ответ, ибо у меня в то время была не только полная борода, закрывающая галстук, но и волосы до лопаток как у битлов.

Заграницу, даже в соцстраны, на научные мероприятия в то время мы еще не ездили, для чего были отобраны специальные, более достойные и внушающие особенное доверие люди. Правда, иногда удалось опубликовать свои тезисы в сборниках международных конгрессов историков медицины, порадоваться, и этого было достаточно. Обыкновенно ездили одни и те же москвичи во главе с Петровым, из республик - единичные представители. Даже изворотливому Арону не сразу удалось попасть в состав советских делегаций. Легче было попасть на симпозиумы историков медицины СССРГДР, которые поочередно проходили то в одной, то в другой стране через каждые два года. Мы с Виктором обыкновенно на них присутствовали, если они проходили в Союзе.

Иногда в своих беседах мы затрагивали вопрос профессионализма, ибо для нас обоих история медицины являлась хлебом насущным, мы жили ею и от нее. Одно дело заниматься профессиональным образом, но совсем другое - достигнуть необходимого профессионального уровня. Здесь существовала целая иерархическая классификация: профессионал, любитель, дилетант, профан. Если Заблудовский сам себя считал лишь любителем, а профессионалом - Карла Зудгофа, то на каком же уровне находились мы 


\section{А. Виксна}

с Виктором? Наверное, дилетанты. Но и профаны делились подробней: знающие и незнающие, тихие и буйные. Воинствующий дурак - это было самое глубокое и горькое несчастье, но как много таких людей было в нашей историко-медицинской среде, настойчиво навязывающих свою глупость другим, которые в свою очередь, желая этого или нет, вынуждены были прислушиваться и подчиняться.

Почему же так случилось, в чем причина, почему в нашей среде было столь мусора? Наверное потому, что большинство наших коллег рекрутировались из неудачников.

Во первых, среди них были бывшие номенклатурные работники, которые из-за неповоротливости или по другим причинам были выброшены из привычной среды, скажем, бывшие ведущие работники здравоохранения. Они умели выступать, руководить, организовать, что само по себе было не плохо, но к истории относились с пренебрежением, скажем, там же все ясно: раньше - плохо, при советской власти - хорошо, плюс еще борьба материализма с идеализмом. Основным источником для них служила передовая газеты "Правда".

Вторую группу составляли просто неудачники, которые серьезными делами заниматься были неспособны и историю медицины избрали как наиболее легкое ремесло в ихнем понятии. По своему мышлению, а также работоспособности они мало отличались от первой группы и были обречены к пустяковым, их мало интересующим занятиям.

И лишь потом шли люди, по настоящему любящие и уважающие свою профессию историка медицины. Таких было мало, наверное также и по причине низкооплачиваемости труда, и к ним относился также Виктор. История медицины для этих людей - не легкая прогулка, развлечение или наслаждение жизнью, а неутомымая и тяжелая работа, которую надо любить страстно и по настоящему, подобно тому, как в молодости свою первую девушку, но с той разницей, что история медицины останется для всей жизни, и, чем старше мы станем, тем больше будем ее любить, ведь разум прибавляется с годами также как независимость души. Долго надо готовиться, и все, что мы за долгие десятки лет сочинили и опубликовали, это только шеренга ступеней к истинной цели понимания того, откуда и каким образом мы пришли и куда пойдем и двинемся и чего достигнем или нет. Хотя и возможно, цель не так важна, сколько сам процесс движения. В тот момент, когда кажется, что чего-то уже достиг и радуешься, намного яснее проявляется именно то, чего недобылся.

Виктор Калнин был настоящим историком медицины и опубликовал около тысячы работ (здесь необходимо учитывать, что в то время публиковаться было не так легко - контроль и всякие преграды). Он был трудолюбивым, самокритичным и требовательным к себе, можно даже сказать - фанатически приверженным к своей дисциплине и профессии. 
Подробная характеристика литературного наследия доцента Калнина не относится к разделу личных воспоминаний, поэтому касаться его не буду. Скажу только, что основную цель, которую Виктор должен был достигнуть и к которой был способен и вполне, даже отлично подготовлен - написанию полноценной истории медицины Эстонии - он не достиг или, иначе говоря, достиг с определенными оговорками, т. е., если и нет солидного тысячелистного тома в кожанном переплете и с золотистыми буквами на спинке переплета, то по-существу все главные разделы он все же написал. Мне кажется, что помешала чрезмерная скромность и робкость Виктора, зависимость его от других, которые приписывались соавторами, хотя и в основном работу делал Виктор сам и один. Но это не так уж важно - его цитировали, цитируют и еще долго будут цитировать, ибо свое, при том, небоюсь сказать, почетное место в историографии он уже занял, и еще долго придется ждать, пока в Эстонии появится равноценный ему наследник исследователь.

Если классиком балтийской историко-медицинской литературы мы привыкли считать Бренсона, то по отношению к Эстонии на втором месте и ближе к современности находится Калнин. Он родился годом после смерти Бренсона, и вполне возможно, что следующий более заметный эстонский историк медицины ныне обучается где-то в первом классе, и, находясь на пороге третьего тысячилетия, его можно будет увидеть, скажем, где-то после 2030 года, до чего нам уже недожить. Нечасто появляются такие крупные историки медицины, как Виктор Калнин, и не беда, что в настоящее время в Эстонии их нет. За полвека один - достаточно для обобщений.

Возвращаясь к нашему личному общению, еще пару слов о последних встречах, когда мы уже достигли такого уровня, что один другого понимали с полуслова, вот, так тесно мы сблизились в своем мышлении и мнениях, а также о критике в адрес Виктора, которую мне приходилось слышать из уст некоторых коллег.

В конце восьмидесятых лет, когда настроение общества и народа стало сильно меняться и выразилось наружу и в более открытом виде, многие спешно начали менять свои взгляды. Помню, что Хейно Густавсон как-то иронизировал, якобы Виктор плакал во время похорон Сталина (в то время он был студентом), и что он даже сталинист. Очевидцем я не был (Густавсон в 1953 году также), но знаю, что некоторые статьи о соратниках Ленина в Тартуском Университете он действительно написал. Эти статьи (опубликованы около 1970 года, когда праздновалось столетие) были обоснованы на строгом фактическом материале и ныне могут быть оценены как принужденная, но необходимая дань той эпохе, в которой мы жили или вынуждены были жить и трудиться.

Виктор от своих коллег эстонцев получил также критику за то, что многие свои статьи опубликовал на русском языке. Здесь мы пришли к единому 


\section{А. Виксна}

мнению, что надо пользоваться тем языком, который в соответствующий период обозрения был господствующим или официально принятым в документации, например, по отношению к Тартускому Университету: когда тот был Дерптским - немецким языком, Юрьевским - русским, в период национальной независимости - эстонским, в советское время - к сожалению, снова русским. Ведь на таком языке в соответствующий период документы, и исследователю удобней и понятней (сколько неудобств в транскрипции фамилий, знает каждый). Но язык сам по себе невиноват, вот, например, эти строки я тоже пишу на русском языке, при помощи которого общался с Виктором.

Но что же касается национальной стойкости Виктора, он был настоящим эстонцем, любил свою родину, и Латвию также, ибо в его жилах текло немножко латышской крови. Зимой 1989 года, когда за неоспоримые заслуги перед историей медицины ему присудили и вручили награду П. Страдыня, он мне подарил эстонский национальный настольный флажок, который стоял в моем рабочем кабинете до прошлого года, т. е., до того времени, пока в связи с избранием в университет Арон меня не выгнал из музея.

Были и встречи попозже, но в конце жизни Виктора все реже и реже, ибо он болел и стал как-то пассивней. Но вечер после вручения награды 11 февраля 1989 года я помню ясно и четко. Поздно вечером двоем в темноте мы стояли в конце длинного перрона рижского вокзала и ожидали таллинсского ночного поезда. Погода была неприятная - дождь, снег, слякоть, грязь, почти так же, как примерно десять лет тому назад, когда мы виделись в Тарту в кризисные для Виктора дни. Но ситуация была совершенно иная. Виктор был радостным и довольным, предложил выпить, но, зная состояние его здоровья, я отказался, что он с признанием принял. Мы долго беседовали, ибо поезд не подходил, о нашей жизни, стремлениях, Виктор, кажется, чувствовал себя полным сил, замыслов и стремлений к великим деяниям в нашей области истории медицины. Мне также было приятно за Виктора, наше прощальное рукопожатие было крепким и дружественным. Угас красный огонек поезда в темной мгле, и я отправился домой.

На похоронах Виктора я не присутствовал, в Тарту приехал лишь в октябре 1993 года на очередную балтийскую конференцию и взял с собой из Риги цветы. Как раз в то время в Москве проходил обстрел Белого дома, что можно было смотреть по прямой американской передаче в нашем телевидении, ситуация была очень тревожной. Вместе с Майей мы пошли на кладбище. Она рассказывала, что Виктор не только имел латышское происхождение со стороны деда, но и в его паспорте, а также в паспорте его сына, который ныне в Америке, записано - латыш.

Круг закончился. Начинается новый круг. Виктор остался в моем сердце, а своими трудами - в эстонском народе. 
Из Омара Хайяма:

Откуда мы пришли? Куда свой путь вершим?

В чем нашей жизни смысл? Он нам непостижим.

Как много чистых душ под колесом лазурным

Сгорает в пепел, в прах, - а где, скажите, дым?

17 августа-2 сентября 1999 года,

г. Цесвайне-Рига

\section{Memories about Viktor Kalnin (Summary)}

\section{By Arnis Vīksna}

The article focuses on the author's memories about Dr. Viktor Kalnin (19291992) who was a medicine historian. The article is written on the 70th birthday of the doctor which was celebrated on the 17th of September 1999 in the University of Tartu.

Arnis Vīksna, Dr. med.

Latvijas Universitātes Medicīnas fakultātes profesors arnis.viksna@lu.lv 